\title{
Perfiles profesionales en la adaptación de series televisivas
}

\author{
Isadora García Avis ${ }^{1}$ \\ Patricia Diego González²
}

Recibido: 2016-12-20

Enviado a pares: 2017-01-27
Aprobado por pares: 2017-04-24

Aceptado: 2017-05-15

DOI: 10.5294/pacla.2018.21.2.3

Para citar este artículo / to reference this article / para citar este artigo

García, I y Diego, P. (2018). Perfiles profesionales en la adaptación de series televisivas.

Palabra Clave, 21(2), 310-337. DOI: 10.5294/pacla.2018.21.2.3

\section{Resumen}

Los remakes transculturales de series de ficción no son un fenómeno nuevo, pero sí constituyen un tipo de adaptación cada vez más frecuente en las pantallas televisivas de todo el mundo. Desde el punto de vista de la producción audiovisual, la investigación académica desarrollada hasta el momento sobre estos procesos es aún escasa. Por ello, resulta imprescindible definir los distintos perfiles profesionales que participan tanto en la compraventa como en la producción de este tipo de adaptaciones. Con dicho objetivo como punto de partida, el presente artículo combina la revisión de la literatura existente sobre los agentes de la producción televisiva con entrevistas a cinco profesionales de la industria. La conjunción metodológica de estas dos dimensiones (la académica y la práctica) permite ofrecer una categorización más completa de estos perfiles televisivos y de sus funciones. Aunque muchas de las figuras que participan en la creación de remakes también están presentes en otros tipos de producciones televisivas, este análisis posibilita la identificación de aquellas cuyos roles cobran es-

1 orcid.org/0000-0003-4663-7931. Universitat Internacional de Catalunya, España. igaravis@uic.es

2 orcid.org/0000-0002-7616-2474. Universidad de Navarra, España. pdiegon@unav.es 
pecial relevancia en el caso concreto de los remakes transculturales: el consultor oflying producer, las distribuidoras y los agentes o representantes. La sistematización de dichos perfiles y sus objetivos y funciones dentro de las distintas fases que conlleva la adaptación de una serie televisiva contribuyen a un mayor entendimiento de este fenómeno a escala global.

\section{Palabras clave}

Televisión; series de ficción; adaptación; formatos; producción (Fuente: Tesauro de la Unesco). 


\section{Professional Profiles in the Adaptation of Television Series}

\section{Abstract}

Cross-cultural remakes of fiction series are not a new phenomenon, but they do constitute an increasingly frequent type of TV adaptation around the world. From the point of view of audiovisual production, the academic research conducted about these processes is still scarce. It is therefore essential to define the different professional profiles involved both in the purchase and sale and in the production of this type of adaptations. This paper combines the review of existing literature about the agents of television production and interviews with five professionals in the industry. The methodological conjunction of these two dimensions (academic and practical) allows us to offer a more complete categorization of these television profiles and their functions. Although many of the figures involved in the creation of remakes are also present in other types of television productions, this analysis enables the identification of those whose roles are particularly relevant in the specific case of cross-cultural remakes: the consultant or flying producer, distributors and agents or representatives. The systematization of these profiles and their objectives and functions within the different phases involved in the adaptation of a television series contribute to a greater understanding of this phenomenon on a global scale.

\section{Keywords}

Television; fiction series; adaptation; formats; production (Source: Unesco Thesaurus). 


\section{Perfis profissionais na adaptação de séries televisivas}

\section{Resumo}

Os remakes transculturais de séries de ficção não são um fenômeno novo, mas sim constituem um tipo de adaptação cada vez mais frequente nas telas da televisão de todo o mundo. Desde o ponto de vista da produção audiovisual, a pesquisa acadêmica desenvolvida até o momento sobre estes processos ainda é escassa. Por isso, é imprescindível definir os diferentes perfis profissionais que participam tanto na compra e venda quanto na produção deste tipo de adaptações. Este artigo combina a revisão da literatura existente sobre os agentes da produção de televisão com entrevistas a cinco profissionais da indústria. A conjunção metodológica dessas duas dimensiones (a acadêmica e a prática) permite oferecer uma categorização mais completa destes perfis da televisão e de suas funções. Ainda que muitas das figuras que participam na criação de remakes também estejam presentes em outros tipos de produções de televisão, esta análise possibilita a identificação daquelas cujos papéis adquirem especial relevância no caso concreto dos remakes transculturais: o consultor ou flying producer, as distribuidoras e os agentes ou representantes. A sistematização destes perfis e seus objetivos e funções dentro das diferentes fases envolvidas na adaptação de uma série de televisão contribuem para um maior entendimento deste fenômeno em escala global.

\section{Palavras-chave}

Televisão; séries de ficção; adaptação; formatos; produção (Fonte: Tesauro da Unesco). 


\section{Introducción}

La adaptación de formatos en televisión no es un fenómeno nuevo, sino que ha existido desde los orígenes del medio. De hecho, Chalaby (2016) identifica tres etapas en su evolución: 1) invención (de la década de 1940 a la década de 1970), 2) internacionalización (durante las décadas de 1980 y 1990) y globalización (a partir de la primera década del siglo XXI). En esta tercera etapa, el panorama televisivo se caracteriza, de un modo especialmente significativo, por una "dinámica de adaptación" (Moran y Malbon, 2006, p. 11), tanto en contenidos de ficción como de entretenimiento. En el caso de los formatos de ficción, en la última década, se ha producido un notable incremento en la producción de remakes de series extranjeras. Según datos de The Wit (2014), mientras que en 2003 solo se emitieron 21 adaptaciones de series en todo el mundo, en 2013 esta cifra alcanzó los 96 remakes. Además, tal informe sitúa a España como el cuarto país del mundo (y el segundo de Europa, por detrás del Reino Unido) en exportación de formatos de ficción. A la hora de adaptar formatos, en España se suele optar más por importar programas de entretenimiento, pero en los últimos años también se han adaptado, con mayor o menor éxito, varias series. Como ejemplo, se podrían mencionar los casos de La chica de ayer (Antena 3, 2009), remake de la serie británica Life on Mars (BBC1, 2006-2007), o Web Therapy (Movistar \#0, 2016-), remake de una serie norteamericana del mismo título (Web Therapy, Showtime, 2011-2015).

A pesar de la proliferación de este fenómeno a escala global, la investigación académica sobre estos procesos de producción televisiva sigue siendo aún escasa. Por esta razón, resulta necesario abordar desde la academia cuestiones como la jerarquía de las distintas figuras que constituyen el engranaje de la compraventa y la producción de un remake en televisión. El objetivo del presente artículo, por tanto, persigue definir y analizar los perfiles profesionales que participan en las distintas fases de adaptación de una serie.

La hipótesis de la que parte este trabajo considera que, aunque la mayor parte de las figuras profesionales que participan en la producción de un remake televisivo son comunes a cualquier tipo de contenido creado dentro de dicho medio, existe una serie de perfiles y tareas propias de este fenóme- 
no concreto. Por ello, el interés descriptivo de la categorización de los roles profesionales cobra especial relevancia en el caso de los remakes de series de ficción. Es innegable que todo proceso de producción televisiva pivota en torno a dos piezas fundamentales: 1) las cadenas y 2) las productoras. Las primeras programan y emiten contenidos, actuando al mismo tiempo como clientes y financieros, mientras que las segundas son las proveedoras de dichos contenidos (Diego, 2005; Fernández-Quijada, 2009). Ahora bien, este artículo pretende demostrar que, en los casos de compraventa y adaptación de formatos, también adquieren un papel sustancial otros agentes, como las distribuidoras, o figuras aún más específicas, como los consultores o los representantes.

\section{Metodología}

A la hora de identificar los distintos perfiles que intervienen en el proceso de adaptación de series televisivas, se ha optado por elaborar una clasificación basada en cuatro grandes categorías, que parten de los agentes mencionados arriba: cadenas de televisión, productoras independientes, distribuidoras de contenidos y otros agentes específicos. Para poder reflejar las distintas relaciones que se establecen dentro de dichas empresas audiovisuales de un modo más claro, también se han tenido en cuenta los dos niveles (el "nivel ejecutivo" y el "nivel práctico o técnico") señalados por Diego (2005, pp. 28-29) y Pardo (2014, p. 51) respecto de la responsabilidad en la toma de decisiones. Sobre el nivel ejecutivo recae la responsabilidad de definir el proyecto en sus dimensiones más importantes (creativas, técnicas y económicas). Este nivel estaría representado por los productores ejecutivos, como los directores de producción de la cadena y de la productora, siendo los primeros el "núcleo duro" que origina y pone en marcha el proyecto. Entre ambos desarrollan el producto que la cadena necesita y acuerdan la modalidad de producción necesaria. Una vez definido el proyecto y asignados los principales recursos, el nivel ejecutivo delega en el nivel técnico la elaboración del producto y, por tanto, la gestión diaria de esos recursos. Este nivel se personaliza en los profesionales en quienes los productores ejecutivos han delegado la realización del proyecto, y llega hasta el último miembro del equipo de producción. 
Cabría señalar que existen otros modos de aproximarse a los distintos agentes que intervienen en este tipo de procesos televisivos. Por ejemplo, Uribe-Jongbloed y Espinosa-Medina (2014, pp. 38-39) establecen un modelo para clasificar a quienes ellos denominan "transductores culturales", es decir, los distintos intermediarios que trabajan entre mercados culturales y que se encargan de los procesos de transducción. Según estos autores, dichos agentes se dividen en función de la naturaleza de sus tareas: scouts (buscadores), merchants (mercaderes) y alchemists (alquimistas). Siguiendo este modelo, en el caso concreto de las adaptaciones de series de ficción, los scouts son quienes participan en la búsqueda del formato; los merchants, quienes negocian su compra; y los alchemists, quienes lo transforman y lo adaptan a su nuevo entorno cultural.

A pesar del interés teórico que puedan despertar propuestas como la señalada por Uribe-Jongbloed y Espinosa-Medina, este artículo pretende sistematizar los principales agentes que participan en la producción de remakes desde la perspectiva práctica de la propia industria televisiva. Por ello, se ha optado por establecer una clasificación que gire en torno a las cuatro categorías ya mencionadas, en la que, además, se consideren los dos niveles (ejecutivo y técnico) presentes en la toma de decisiones. Dentro de cada grupo se describirán los rasgos característicos de los distintos profesionales que intervienen en este tipo de procesos televisivos.

Es necesario señalar que no existe un consenso preciso sobre algunos de los títulos que designan dichos perfiles profesionales; en ocasiones, incluso, se utilizan de manera indistinta. Este artículo, sin embargo, se dispone a perfilar los matices que permiten distinguir cada uno de estos roles. Para ello, se partirá de las investigaciones sobre jerarquía de producción desarrolladas por Pardo $(2002,2014)$ en el campo de la producción cinematográfica, ampliadas posteriormente por Diego (2005) en la producción de series televisivas y por Guerrero $(2010,2013)$ en la producción de programas de entretenimiento. En este caso concreto, los conocimientos asentados por los autores mencionados se han extrapolado al ámbito de los remakes televisivos de series de ficción. Además, la investigación académica sobre estos perfiles no solo se ha basado en una revisión bibliográfica, sino 
que se ha completado y enriquecido con cinco entrevistas en profundidad a profesionales de la industria televisiva, que han participado en distintas fases del proceso de adaptación de una serie: Duncan Cooper (International Executive Producer, BBC Worldwide), María García-Castrillón (ejecutiva de ventas de Boomerang TV International), Darío Madrona (guionista, coordinador de guiones y productor ejecutivo de la productora DobleFilo), Ignacio Manubens (subdirector de ficción de Atresmedia Televisión) y Gregorio Quintana (ex director general de ficción de la productora Boomerang TV). Las entrevistas, realizadas entre 2013 y 2016, eran semiestructuradas y partían de un cuestionario de preguntas abiertas. En su mayoría, dichas preguntas estaban planteadas en función de la experiencia y de los casos específicos en los que había participado cada profesional. A estas se añadían otras que eran comunes para todos los perfiles. Tres de las entrevistas se realizaron en persona (Cooper, Madrona y Quintana), mientras que las otras dos (García-Castrillón y Manubens) fueron por vía telefónica. Las aportaciones de estos profesionales han resultado fundamentales para corroborar la existencia de las figuras propiamente características de los procesos de adaptación de formatos televisivos. Gracias a sus testimonios, ha sido posible identificar y comprender las tareas que debe desempeñar cada una de las figuras involucradas en este tipo de procesos, especialmente en el caso de los perfiles más recientes (como los analistas de $\mathrm{I}+\mathrm{D}$ ) y más diferenciales (como los consultores).

A continuación, se procederá a detallar los perfiles profesionales más significativos dentro de los cuatro grandes grupos ya mencionados: cadenas, productoras, distribuidoras y otros agentes específicos.

\section{Cadenas de televisión}

Cada cadena televisiva tiene sus propias infraestructuras, y se organiza en función de sus características, necesidades e intereses. Esto es algo que inevitablemente repercutirá en su manera de abordar el proceso de adaptación de un formato de ficción. Por ejemplo, las estrategias programáticas, las estructuras financieras y los modos de trabajo variarán considerablemente entre una cadena pública financiada a través de impuestos, una cadena comercial generalista y una cadena de pago. Otros factores por tener en cuenta 
serían los rasgos propios de los mercados televisivos de cada país o el hecho de que una cadena comercial esté integrada dentro de un grupo mediático concreto. Incluso entre cadenas del mismo tipo, dentro del mismo país y pertenecientes al mismo grupo se pueden apreciar diferencias considerables.

Sin embargo, independiente de estas peculiaridades, la estructura jerárquica de las cadenas televisivas suele tener elementos comunes. Dentro de su engranaje existen distintos departamentos que se ocupan de cuestiones como la gestión de contenidos o la programación de la parrilla, y que dependen del director general de la cadena (Bustamante, 1999). Dichos departamentos tendrán que trabajar juntos a menudo, coordinándose para sacar un proyecto adelante. Este artículo se va a centrar solo en las dos divisiones de la cadena más relevantes para el estudio de las adaptaciones: el departamento de ficción (que se encuentra dentro de la estructura de contenidos) y el departamento de distribución o ventas (que pertenece a la estructura de gestión, y que se analizará en el apartado dedicado a las distribuidoras). Las funciones de estas dos áreas siempre son las mismas: desarrollar nuevos proyectos y supervisar la producción de las series compradas por la cadena, en el caso del departamento de ficción; y vender los derechos de sus programas televisivos, en el caso del departamento de ventas.

\section{Jerarquía en el departamento de ficción de una cadena}

La figura 1 muestra la estructura jerárquica habitual del departamento de ficción dentro de una cadena televisiva.

\section{Nivel ejecutivo de la toma de decisiones}

Director (general) de ficción (head of drama/scripted programming). Se trata del responsable último de los contenidos de ficción de una cadena. Tiene una visión global de todos los contenidos de ficción (series, seriales, miniseries o TV movies) que se están desarrollando, produciendo y emitiendo en su cadena. Suele contar con el apoyo de un subdirector, en quien delega algunas de sus tareas. El director de este departamento marca la línea estratégica por seguir en el desarrollo de nuevos proyectos y, en el caso de los remakes, es quien toma las decisiones finales respecto de la adaptación de un formato concreto. Junto con el director general y otros altos ejecutivos 
Figura 1. Jerarquía de ficción (cadena). Leyenda: gris oscuro y en negrita (nivel ejecutivo); gris claro (nivel técnico).

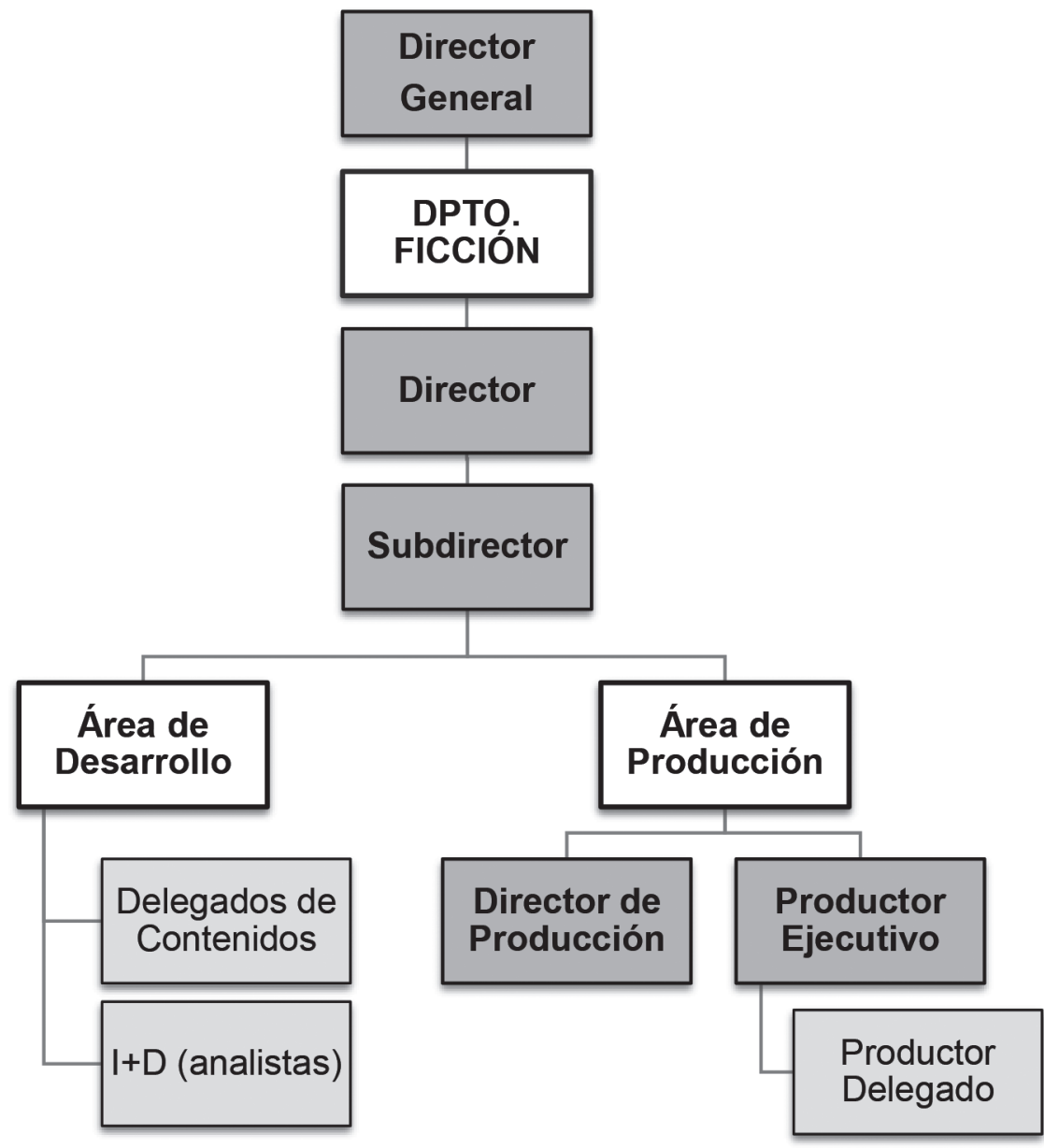

Fuente: Elaboración propia.

de la cadena (como el director de programación o emisiones) decide qué proyectos se ponen en marcha y de qué forma, así como la cancelación de un espacio (Guerrero, 2013). Un director de ficción esboza tanto la arquitectura general de los contenidos de ficción de una cadena como la de cada proyecto concreto, encarga su producción a productoras y supervisa todos los aspectos (creativos y financieros) de su desarrollo, siempre en función de los recursos y las necesidades de la cadena. 
Productor ejecutivo (executive producer). Este cargo ostenta el rango de máxima responsabilidad en el desarrollo y la producción de una serie. En ocasiones, se puede identificar con el director de ficción de la cadena, aunque lo habitual es que el director de ficción cuente con varios productores ejecutivos en plantilla a su cargo, cada uno de los cuales trabajará en una serie o series concretas. Todo productor ejecutivo es, esencialmente, un decision-maker y un project manager (Pardo, 2002, p. 49). Se trata de una figura que debe tomar las decisiones más adecuadas para cada proyecto y gestionar la logística de la producción. Es el responsable creativo y económico del proyecto, la persona que se responsabiliza de su nacimiento, desarrollo y resultado final (Diego, 2005). En el caso de los remakes televisivos, al igual que sucede con cualquier serie de ficción, el productor ejecutivo de la cadena será quien controle el desarrollo del proyecto, desde sus orígenes hasta su emisión. Supervisará todos los aspectos relacionados con la producción de la serie, tanto económicos como de contenido, y tendrá la última palabra en la toma de decisiones sobre el proceso de adaptación.

Director de producción (production manager). Es la persona responsable de la adecuación de los recursos a las necesidades de producción de una cadena, sin entrar en el terreno de los contenidos. Entre otras tareas, se encarga de desarrollar un estudio de la viabilidad del proyecto, para después poder elaborar un presupuesto que permita llevarlo a cabo. Este directivo suele coincidir con el responsable de la división de producción de toda la cadena, y tiene a su cargo gerentes o responsables de producción que supervisan más de cerca los distintos tipos de contenido (Diego, 2005; Martínez y Fernández, 2011).

\section{Nivel técnico de la toma de decisiones}

Productor delegado (production supervisor). El productor ejecutivo delega en este cargo la producción de una serie concreta. Es la persona responsable del día a día de su producción. En las series españolas, esta figura puede aparecer en los títulos de crédito como productor delegado o productor ejecutivo. Dado que rinde cuentas directamente ante el productor ejecutivo de la cadena, a quien va informando de la evolución de la serie, debe mantener una relación fluida con él. Entre las funciones más destacadas de este agente, se encuentran la supervisión del desarrollo, la grabación de la 
serie, el control presupuestario de cada capítulo, y el velar por el cumplimiento del contrato entre productora y cadena (Cuevas, Gómez y Faerna, 1994; Diego, 2005).

Delegado de contenidos (development executive). Mientras que el productor delegado trabaja en el ámbito directo de la producción, los delegados de contenidos se centran en los proyectos de ficción desde la perspectiva del desarrollo y el análisis de historias. Son los responsables de leer los distintos documentos de guion de posibles nuevos proyectos y los guiones de las series que ya están en producción. Después, devuelven esos documentos a la productora, con las observaciones, los comentarios y las sugerencias de la cadena. Por ello, la relación entre el delegado de contenidos y la productora debe ser muy directa. El objetivo último de su trabajo radica en supervisar el desarrollo de un proyecto, desde sus orígenes hasta el guion del último capítulo, para garantizar que su contenido responde a lo solicitado por la cadena. En el caso de los remakes, la supervisión de contenidos por parte de la cadena presenta un reto particular: la dificultad de traspasar elementos narrativos pensados para un público determinado a un nuevo contexto, con unos espectadores muy diferentes.

Analistas de $\mathrm{I}+\mathrm{D}$. Dentro del área de $\mathrm{I}+\mathrm{D}$ de una cadena pueden trabajar uno o varios analistas, dependiendo de cuestiones como el tamaño o la organización interna de la empresa. Esencialmente, en este departamento se estudian los formatos de ficción que están despuntando en otros lugares y las distintas tendencias más relevantes a escala global. Su trabajo resulta muy útil para determinar si un formato o una tendencia concreta podrían tener éxito en la parrilla de la cadena (entrevista a Ignacio Manubens, 12 de febrero de 2016).

\section{Productoras independientes}

Como sucede en el caso de las cadenas, no todas las productoras se organizan del mismo modo. Dependiendo de su tamaño, de sus modos de trabajo o del tipo de proyectos que aborde, cada productora presentará una estructura diferente. Los rasgos de cada mercado televisivo y la posible pertenencia de una productora a un gran grupo mediático también son factores 
que pueden condicionar su estructura y su organización interna. Además, las productoras pueden estar especializadas en ficción o en entretenimiento o contar con subdivisiones que se encarguen de producir distintos tipos de contenido, habitualmente bajo encargo previo de los canales televisivos (Fernández-Quijada, 2009).

A pesar de estas diferencias, es posible establecer un paradigma organizativo para mostrar la jerarquía estándar de aquellas figuras, fundamentales en el proceso de producción de una serie, que forman parte de (o trabajan para) el área de ficción de una productora. Respeto de la adaptación de formatos televisivos, las productoras con infraestructuras más complejas pueden tener, además, un brazo de distribución o ventas, dedicado a vender sus formatos en el extranjero. Cabría señalar que, sobre todo en las productoras de menor tamaño, algunos de estos roles pueden ser desempeñados por una misma persona. Por ejemplo, el director de ficción puede actuar también como productor ejecutivo.

\section{Jerarquía en el departamento de ficción de una productora}

\section{Nivel ejecutivo de la toma de decisiones}

Director (general) de ficción (head of drama/scripted programming). De modo similar al trabajo desempeñado por su homólogo en la cadena, el director de ficción es el responsable último de las series desarrolladas y producidas por una productora independiente. En función del tamaño y la estructura de la empresa, puede tratarse del máximo cargo directivo o trabajar para un director general de contenidos. Posee una visión global de todos los proyectos de la productora, supervisa la evolución de cada serie, marca los criterios por seguir y se encarga de las negociaciones con la cadena. En cada proyecto, el director de ficción se dedica fundamentalmente a 1) establecer las directrices por seguir, 2) supervisar el desarrollo general de la serie y 3 ) aglutinar y proteger a un equipo tanto artístico como técnico (entrevista a Gregorio Quintana, 16 de diciembre de 2013).

En el caso de los remakes televisivos, esta figura será la encargada de marcar los criterios de contenido fundamentales que van a definir el desarrollo de la adaptación y elegir al equipo técnico y artístico que se encargará 
Figura 2. Jerarquía de ficción (productora)

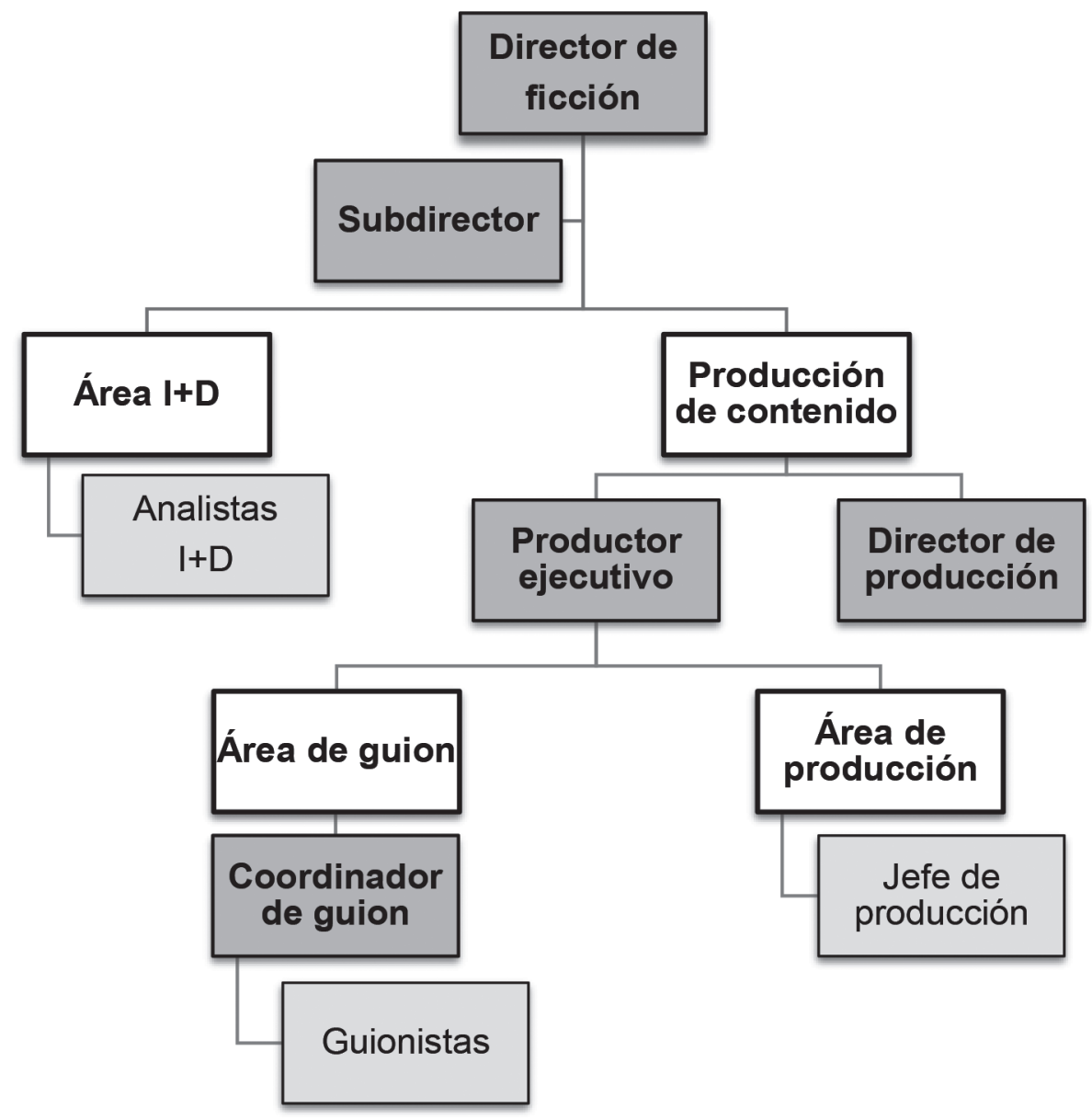

Fuente: Elaboración propia.

de dar forma a la nueva serie. Además, el director de ficción irá supervisando la evolución del proyecto durante las distintas etapas de su producción, y también mantendrá una relación fluida con los directivos de la cadena durante todo el proceso.

Productor ejecutivo (executive producer). Este cargo es equivalente al del showrunner, en las industrias televisivas en las que existe dicha figura. Se trata, por tanto, del responsable último de una serie dentro de la productora. Este productor ejecutivo pone en marcha el proyecto y lo desarrolla 
en todos sus frentes, en estrecha comunicación con el productor ejecutivo y el productor delegado de la cadena para la que realiza la serie. Las grandes empresas pueden contar con varios productores ejecutivos en plantilla, cada uno de los cuales trabajará en una serie concreta. En algunos casos, además, puede haber varios productores ejecutivos (o co-showrunners) al mando de una serie (Diego, 2005).

Las funciones de este productor son similares a las de su homólogo en la cadena, con la salvedad de tener, en muchos casos, una mayor implicación creativa. El rol del productor ejecutivo ha adquirido una relevancia excepcional en la ficción televisiva, recogiendo facetas dispersas en el trabajo del productor, del director y del guionista cinematográficos (Villagrasa, 1992). Así, todo productor ejecutivo debe ejercer su trabajo compaginando dos vertientes: 1) la logística (producción) y 2) la artística (contenido). Entre sus tareas destacan la supervisión de la biblia de la serie, la elaboración del presupuesto y la confección del plan de producción. Dichas tareas son las mismas tanto en los remakes como en las series basadas en ideas originales. La única diferencia radica en que, en el caso de las adaptaciones, el productor parte de una serie ya existente para desarrollar su trabajo. Por ello, deberá conocer esa serie a la perfección, para así tomar las decisiones (tanto conceptuales como logísticas) más adecuadas a la hora de adaptarla.

Director de producción (production manager). Al igual que su homólogo en la cadena se encarga de gestionar los recursos materiales, humanos y financieros de la compañía. Como responsable de todos los aspectos económicos de una serie televisiva, es quien establece el presupuesto y asigna su control al jefe de producción. Entre sus funciones, destaca conseguir todo lo necesario (desde equipos técnicos a las distintas localizaciones) para la grabación de la serie. Junto con el jefe de producción, lleva a cabo la contratación del personal, tanto artístico como técnico. También trabaja con el productor ejecutivo en la elaboración del calendario de producción (Diego, 2005).

Coordinador de guion (supervising producer, head writer). Es la figura del equipo con mayor responsabilidad en el desarrollo creativo del contenido. El productor ejecutivo (o el showrunner, si lo hubiera) delega la su- 
pervisión del contenido de la serie y de sus guiones en este coordinador, que habitualmente también es uno de los guionistas. Básicamente, su trabajo consiste en liderar las reuniones con los demás guionistas, en las que se establece el mapa de tramas de la temporada y la estructura de cada episodio. Después, cada guionista escribe por su cuenta los episodios que se le han asignado, y que posteriormente serán revisados tanto por el coordinador de guion como por el productor ejecutivo. En el caso de los remakes televisivos, el coordinador de guion es, en última instancia, el responsable de desarrollar el proyecto de adaptación del formato comprado (entrevista a Darío Madrona, 28 de noviembre de 2013).

\section{Nivel técnico de la toma de decisiones}

Jefe de producción (line producer). El productor ejecutivo y el director de producción delegan en esta figura todos los detalles de la producción de una serie concreta. Se trata, por tanto, de la persona que lleva a cabo el trabajo de campo durante el día a día de la grabación. El jefe de producción "desempeña un papel fundamental para que el programa se realice dentro de los tiempos y los objetivos marcados", ya que se responsabiliza "de la organización de la grabación y de la disponibilidad de todos los medios a emplear" (Herrero y García, 1987, p. 56). Entre sus funciones, se encuentran tareas como vigilar el cumplimiento del plan de grabación o realizar un control diario del presupuesto. Dentro de este nivel técnico, y a las órdenes del jefe de producción, trabajan los ayudantes y auxiliares de producción, así como el secretario (contable o administrativo) de producción (Diego, 2005).

Guionistas (screenwriters). Dan forma a la historia, y lo hacen trabajando bajo la supervisión del coordinador de contenidos y del productor ejecutivo (o del showrunner). Se reúnen periódicamente en la sala de guionistas, donde se establecen las bases generales que van a definir el desarrollo de los personajes y la evolución de las tramas. Después, cada guionista escribe los guiones de los episodios individuales que le han asignado. Tienen que desarrollar su trabajo siguiendo la visión y las coordenadas de contenido establecidas por el productor ejecutivo. Además, deben escribir sus guiones sin generar "un salto perceptible con el trabajo de los otros guio- 
nistas de la serie" (Villagrasa, 1992, p. 111). Es decir, aunque cada episodio haya sido escrito por un guionista diferente, en todos se debe percibir una unidad tonal que permite identificarlos como episodios de una misma serie.

Analistas de $I+D$. Las productoras también suelen contar con esta figura, y su funcionamiento suele ser similar al ya señalado en el caso de las cadenas. En una productora, además, este departamento sirve como laboratorio, ya que en él se desarrollan ideas para posibles nuevos proyectos.

\section{Distribuidoras de contenidos televisivos}

$\mathrm{Al}$ igual que sucede con cadenas y productoras, existen distintos tipos de distribuidoras, cuyo objetivo principal es comercializar las latas y los formatos televisivos en el mercado internacional. Los acuerdos de distribución implican un reparto porcentual de los beneficios obtenidos y una comisión para la distribuidora. Todo esto quedará establecido en el contrato firmado por las partes implicadas (entrevista a María García-Castrillón, 8 de febrero de 2016).

En el caso de la venta de formatos, además de gestionar la cesión de los derechos de adaptación, estas compañías "ponen en circulación la combinación exclusiva de información y experiencia” (Moran y Malbon, 2006, p. 57). Es decir, también aportan el know-how de la producción de un formato, algo que puede resultar muy útil para un comprador potencial. Havens establece un amplio espectro entre las grandes maquinarias de distribución de Hollywood y las pequeñas distribuidoras independientes (solo distributors), y subraya que "una de las mercancías más preciadas para un distribuidor global de televisión radica en su reputación” (2006, p. 41). Según este autor, además, dicha reputación siempre está vinculada a su jerarquía dentro de la industria, a su red de contactos y a los géneros de su programación.

Dependiendo del tamaño de una distribuidora, su jerarquía interna será más o menos compleja, pero en todas se pueden encontrar dos figuras esenciales: 1) el director de ventas, en el nivel ejecutivo, 2) y los ejecutivos de ventas, en el nivel práctico. 
El director (general) de ventas (head of international sales) coordina y supervisa todos los acuerdos de distribución, siempre en función de los intereses y las estrategias marcadas por la junta directiva de la empresa. En el caso de las distribuidoras de mayor tamaño, además, el director general puede tener a su cargo un subdirector $y$ una serie de directores de ventas para distintos territorios.

Los ejecutivos de ventas (international sales executive) son quienes siguen las directrices implementadas en el nivel ejecutivo. Mantienen un trato constante con los compradores de distintos países y acuden a los mercados televisivos internacionales, que se mencionarán más adelante, para promocionar su catálogo de contenidos. Para ello, recurren a herramientas como folletos promocionales que capturan, de manera visual, las cualidades estéticas definitorias de sus programas televisivos (Bielby y Harrington, 2008, pp. 122-123). Los ejecutivos de ventas también negocian las posibles condiciones de cesión de derechos de una serie, y después informan a su director general, que es quien revisa el acuerdo y le da el visto bueno. Como apunta García-Castrillón, dependiendo del tamaño y de los recursos de una distribuidora, su equipo de ejecutivos de ventas será más grande o más pequeño (entrevista a María García-Castrillón, 8 de febrero de 2016).

Para analizar los matices que pueden presentar estas empresas, resulta de gran utilidad recurrir a la clasificación de Steemers (2004, pp. 76-81), quien identifica tres tipos de distribuidoras en la explotación de contenidos televisivos:

1. Las cadenas-distribuidoras (broadcaster-distributors) son las divisiones de ventas propias de las cadenas, sus "brazos comerciales". Se encargan de administrar los derechos de emisión de sus contenidos televisivos (tanto de producción propia interna como externa). En el caso de la producción externa, y dependiendo del acuerdo al que se haya llegado con la productora, en ocasiones la distribuidora de la cadena puede gestionar los derechos de venta de un formato. En el mercado español, lo habitual es que la cadena se quede con los derechos de las latas, mientras que la productora retiene los derechos referentes al formato. Dentro de esta fórmula puede haber distintas 
variables. Por ejemplo, una productora puede ceder los derechos de su formato a una cadena-distribuidora exclusivamente para algunos territorios y así reservarse el acceso a determinados mercados televisivos que le puedan interesar (entrevista a María García-Castrillón, 8 de febrero de 2016).

2. Las productoras-distribuidoras (producer-distributors) son aquellas productoras que cuentan con una división propia de ventas, y que han retenido los derechos para la explotación internacional y secundaria de sus formatos. Como ya se ha mencionado, habitualmente la cadena gestiona los derechos de las latas. Aun así, dependiendo del acuerdo y de la relación que exista entre cadena y productora, en algunos casos la productora-distribuidora también puede comercializar las latas de sus series (entrevista a María García-Castrillón, 8 de febrero de 2016). Aquellas productoras que tienen la infraestructura necesaria para poder constituir su propio departamento de ventas lo hacen, principalmente, para obtener un mayor control sobre la explotación de sus contenidos en mercados internacionales (Steemers, 2004).

3. Distribuidoras independientes (non-aligned distributors). En ocasiones, la venta de latas o formatos no la llevan a cabo directamente ni cadenas ni productoras. Estas pueden llegar a un acuerdo comercial con una distribuidora independiente y cederle los derechos para que represente su serie en el mercado internacional. En la actualidad, este tipo de distribuidoras puede tener dificultades para encontrar su sitio en un mercado copado por grandes empresas, vinculadas a cadenas o productoras. A no ser que cuenten con una trayectoria muy consolidada o que establezcan acuerdos a largo plazo para gestionar los derechos internacionales de alguna cadena o productora, la oferta de contenidos a la que pueden acceder es más reducida. Por ello, más allá de limitarse a vender series ya terminadas, las compañías independientes también suelen recurrir a otras alternativas para participar en la producción de contenidos. Dichas iniciativas pueden incluir, por ejemplo, avances de financiación o acuerdos de coproducción o de preventa (Steemers, 2004). 
Para los distintos agentes que integran estas distribuidoras y, en especial, para los ejecutivos de ventas, el epicentro fundamental del desarrollo de su ejercicio profesional se encuentra en los grandes mercados globales de la industria televisiva. Entre ellos, es imprescindible destacar los casos de MIPTV y MIPCOM, que sin lugar a duda son los dos mayores mercados televisivos que se celebran cada año. ${ }^{3}$ Según Havens (2006, p. 71), este tipo de encuentros tiene un componente ritualístico, que contribuye a construir un sentido de comunidad unitario y global. De modo similar, aunque desde el punto de vista de los compradores que adquieren contenidos en estos mercados televisivos, Kuipers (2012) subraya el carácter de "tribu cosmopolita" que a su juicio se puede atribuir a estos profesionales, identificando rasgos, hábitos y discursos transnacionales. Por último, cabría señalar que, más allá de las dinámicas económicas propias de todo mercado (Havens, 2006, p. 96; Guerrero, 2010, p. 243), el factor interpretativo y de análisis de las variables culturales desempeña un papel fundamental en la compraventa global de productos televisivos (Bielby, 2011 , p. 537). No se puede olvidar que los agentes que participan en estos mercados son, en palabras de Havens, "intérpretes culturales de tendencias globales y domésticas” (2006, p. 96).

\section{Otros agentes específicos: consultores y representantes}

Además de las cadenas, las productoras y las distribuidoras, en el caso de los remakes, también pueden participar otras figuras, cuyas funciones responden a las características particulares de este tipo de procesos, y que por tanto merecen ser destacadas. Así, el presente análisis se completará con la descripción de dos perfiles más: 1) el consultor y 2) el representante.

3 Ambos eventos tienen lugar en Cannes: el primero de ellos, en marzo o abril; el segundo, en octubre. Aun así, es necesario recordar que, además de los grandes mercados internacionales, también existen otros dos tipos de mercados televisivos: 1) de corte regional, dirigidos a territorios geolingüísticos específicos (como DISCOP Africa o MIP Cancun); y 2) mercados temáticos, especializados en determinados tipos de contenidos (como Cartoon Forum, dedicado a la programación infantil, o el mercado de documentales Sunny Side of the Doc) (Havens, 2006, p. 66; Steemers, 2004, pp. 28-30; entrevista a María García-Castrillón, 8 de febrero de 2016). 


\section{Consultores (consultants o flying producers)}

En ocasiones, la compra de un formato estipula la inclusión de un servicio de consultoría para el desarrollo de la adaptación. Moran y Malbon (2006) definen este tipo de consultoría como un servicio de asesoría directa que se ofrece al nuevo comprador de un formato. A través de este proceso de asesoramiento, un productor (u otro ejecutivo del formato original) ofrece sus consejos y recomendaciones al equipo de producción que va a desarrollar la adaptación.

Habitualmente, la productora de la serie original es la que proporciona estos servicios de consultoría, aunque, en ocasiones, puede delegar dichas tareas en otra persona. Las labores del consultor son de naturaleza variada, y su espectro de actuación puede ir desde una sola visita al territorio que va a adaptar el formato hasta un seguimiento más extensivo del desarrollo de la adaptación. Su grado de implicación y el tipo de servicios que proporcionará quedarán establecidos en el contrato de compra del formato. En cualquiera de los casos, el comprador de los derechos deberá pagar una comisión específica de consultoría, más los gastos incurridos por el consultor (Viljoen, 2002).

A pesar de que cada profesional tiene sus propios modos de trabajo, los objetivos y las tareas de todo consultor se pueden encuadrar dentro de unas mismas coordenadas. Duncan Cooper, international executive producer de BBC Worldwide, cuyo trabajo implica labores de consultoría, destaca tres funciones básicas (entrevista a Duncan Cooper, 14 de mayo de 2014):

1. Ayudar a la cadena o productora que ha adquirido un formato a realizar la mejor adaptación posible. La clave está en tres conceptos: tiene que ser una adaptación, tiene que ser de un formato concreto y tiene que ser la mejor para ese mercado local.

2. Hablar y debatir con los compradores sobre todas aquellas cuestiones relacionadas con su país que puedan afectar a la adaptación (como las diferencias culturales), y que impliquen realizar cambios narrativos. El objetivo de un consultor es trabajar con el equipo local para 
crear un programa que encaje en el panorama televisivo de su país y que parezca una producción original autóctona.

3. Proteger el formato y la "integridad de la marca". Independiente de todos los cambios y las transformaciones que implique la adaptación, un consultor vela por que se mantenga el $\mathrm{ADN}$ del programa original.

Aunque pueda haber excepciones, la mayoría de los consultores suelen ser bastante flexibles con los remakes de sus series. Esta figura sigue el desarrollo del proceso de producción, para ver cómo va avanzando la adaptación, pero normalmente no entra a realizar muchas valoraciones sobre el contenido o sobre las decisiones que está tomando la nueva productora. Teniendo en cuenta que la compra de un formato supone una gran inversión económica para la productora, se confía en que el nuevo equipo de producción va a intentar hacer la mejor adaptación posible (entrevista a María García-Castrillón, 8 de febrero de 2016). Por último, es importante destacar que el trabajo del consultor puede tener un impacto positivo en los guionistas y productores de industrias televisivas menos consolidadas. La experiencia y el know-how de los consultores extranjeros puede contribuir a impulsar el desarrollo de la producción en otras industrias locales, especialmente en el caso de pequeñas industrias florecientes (Szostak, 2013,2016).

\section{Representantes 0 agentes (agents)}

Aunque lo habitual en la compraventa de formatos es que el acuerdo se cierre entre un comprador y un vendedor, en ocasiones hay representantes que actúan en nombre de terceras partes. Este tipo de intermediario puede desempeñar un papel muy relevante en algunos mercados concretos, como el de los Estados Unidos. En palabras de David Frank, fundador de la productora RDF Media, "es imposible realizar este trabajo sin agentes. El mercado estadounidense es tan complejo que, si intentases negociar tus propios acuerdos, te comerían vivo" (Moran y Malbon, 2006, p. 71). Es decir, las productoras internacionales negocian con los agentes intermediarios, y esos agentes serán quienes después vendan los formatos directamente a las productoras norteamericanas. Cuando se cierra un acuerdo de venta, la comisión de dichos agentes puede alcanzar hasta $10 \%$ de la tarifa por episodio del formato (Goldsmith, 2001; Moran y Malbon, 2006). 
Habitualmente, estos representantes están vinculados, bien a una productora, bien a una de las agencias que operan en la industria audiovisual y del entretenimiento, entre las que destacan las siguientes: William Morris Agency, Creative Artists Agency, International Creative Management, United Talent Agency y Endeavour Agency. Del mismo modo que estas agencias representan a actores, directores y guionistas, sus agentes también pueden adquirir los derechos de un determinado formato para representarlo en el mercado estadounidense. Sirva como ejemplo el caso de Ben Silverman, que se convirtió en uno de los pioneros de este fenómeno a mediados de la década de 1990, adquiriendo un gran número de formatos de ficción y de entretenimiento para el mercado norteamericano (Goldsmith, 2001). Entre ellos, The Office, Yo Soy Betty, la Fea o ¿Quién quiere ser millonario?

Además de proporcionar una vía de acceso a mercados como el estadounidense, estos agentes pueden ser figuras útiles en otros casos, como cuando el productor tiene poca experiencia en la venta de formatos (Viljoen, 2002). Por su parte, Moran y Malbon (2006, p. 72) señalan que los agentes más respetados y exitosos, sobre todo en el mercado norteamericano, se caracterizan por tener "buenos contactos y una alta credibilidad con las grandes compañías del mercado, especialmente con las networks”. Así, cabría afirmar que un buen agente, además de saber detectar formatos con potencial internacional, debe conocer muy bien los mercados televisivos, contar con muchos contactos y tener una gran capacidad de negociación.

\section{Conclusiones}

A pesar de que cada empresa, país y mercado televisivo presenta sus propias peculiaridades, resulta valioso extraer y estandarizar los rasgos generales más característicos de aquellas figuras que participan en las adaptaciones de formatos de ficción. Aunque la mayor parte de dichos roles se puede encontrar habitualmente en las producciones de ficción televisivas, tres de los perfiles detallados emergen como especialmente significativos en estos procesos de adaptación seriada. Las distribuidoras, el consultor oflying producer y el agente o representante adquieren especial relevancia porque son quienes ejercen de correa de transmisión de los contenidos ya producidos. 
En primer lugar, las distribuidoras, ya sean propiedad de las cadenas, de productoras o de naturaleza independiente, actúan como eslabón clave en el proceso de adaptación, tendiendo puentes y posibilitando el acceso de los creadores de contenido a los mercados televisivos más relevantes del sector. Así, estos mediadores se convierten en empresas indispensables para obtener un mayor alcance en la venta de formatos en el mercado global de la televisión.

En segundo lugar, los consultores (también denominados en el mercado anglosajón con el término de flying producer) intervienen en ciertos procesos de adaptación dependiendo de la naturaleza del proyecto. La utilidad de esta figura queda patente en aquellos casos de formatos de ficción que son particularmente complejos, ya sea desde un punto de vista creativo, o desde el punto de vista del know-how de la producción. Gracias a este profesional, el proceso de adaptación se refuerza con un asesoramiento y consulta personalizados, enriquecidos por la experiencia del propio consultor y por los conocimientos acumulados durante la realización de la serie que está siendo adaptada. El rol del asesor, por tanto, se convierte en una pieza clave durante el proceso de recontextualización del formato. Como consecuencia del desarrollo de su trabajo, los consultores también poseen la capacidad de impulsar, con sus conocimientos y experiencia en producción, otras industrias televisivas menos desarrolladas.

En último lugar, también se debe destacar la figura del representante o agente, cuya importancia es clave en determinados mercados, ya sea porque están especialmente consolidados o porque sus estándares de funcionamiento así lo determinan. El ejemplo más claro de esta situación se encuentra en el mercado estadounidense: un contenido televisivo no creado en dicho territorio solo puede acceder a un mercado tan competitivo a través de un representante. De este modo, los agentes se convierten en intermediarios necesarios para que las negociaciones entre empresas audiovisuales fructifiquen. En este contexto, son esenciales los contactos que posea, tanto profesionales como personales, y su prestigio o credibilidad ante las networks y los grandes studios americanos. 
Aunque las tres figuras aquí recogidas pueden ser identificadas como las más prominentes en los procesos de adaptación de series de televisión, también conviene destacar que los ingredientes para que un formato sea susceptible de ser adaptado tienen que darse y desarrollarse en el nivel ejecutivo de la toma de decisiones de la producción. En este sentido, y como se ha señalado, el perfil más determinante es el del productor ejecutivo. Esto cobra aún más importancia en el caso del productor ejecutivo de la productora, que normalmente es el showrunner de la serie o quien mayor control creativo tiene sobre el proyecto.

La estandarización de los perfiles profesionales detallados en este artículo, en definitiva, da muestras del grado de madurez de las industrias audiovisuales en los albores del siglo XXI. Dentro de la "dinámica de adaptación" de la era televisiva actual, la consolidación de los agentes estudiados contribuye a reforzar los engranajes y mecanismos propios de la adaptación de series en la industria global de la televisión.

\section{Referencias}

Bielby, D. D. (2011). Staking claims: Conveying transnational cultural value in a creative industry. American Behavioral Scientist, 55(5), 525-540.

Bielby, D. D. y Harrington, C. L. (2008). Global TV: Exporting television and culture in the world market. Nueva York: NYU Press.

Bustamante, E. (1999). La televisión económica: financiación, estrategias y mercados. Barcelona: Gedisa.

Chalaby, J. K. (2016). Seventy years in the making: The advent of the transnational television format trading system. En K. Aveyard, A. Moran y P. Majbritt Jensen (eds.), New patterns in global television formats (pp. 63-78). Bristol: Intellect.

Cuevas, A., Gómez, R. y Faerna, J. M. (1994). Las relaciones entre el cinema y la televisión en España y otros países de Europa. Madrid: EGEDA. 
Diego, P. (2005). La figura del productor de ficción en televisión. Communication \& Society, 18(1), 9-30.

Fernández-Quijada, D. (2009). El mercado de la producción independiente en España ante la aparición de Cuatro y La Sexta. Communication \& Society, 22(1), 59-87.

Goldsmith, C. (2001). Brash U.S. Agent Helped Spark British TV Invasion. Wall Street Journal, Eastern Edition, 237(98), sección B1.

Guerrero, E. (2010). El desarrollo de proyectos audiovisuales: adquisición y creación de formatos de entretenimiento. Communication \& Society, 23(1), 237-273.

Guerrero, E. (2013). Guion y producción de programas de entretenimiento. Pamplona: Eunsa.

Havens, T. (2006). Global television marketplace. Londres: British Film Institute.

Herrero, R. y García, F. (1987). Los procesos de producción de series argumentales. Madrid: RTVE.

Kuipers, G. (2012). The cosmopolitan tribe of television buyers: Professional ethos, personal taste and cosmopolitan capital in transnational cultural mediation. European Journal of Cultural Studies, 15(5), 581-603.

Martínez, J. y Fernández, F. (2011). Manual del productor audiovisual. Barcelona: UOC.

Moran, A. y Malbon, J. (2006). Understanding the Global TV Format. Bristol: Intellect.

Pardo, A. (ed.) (2002). The Audiovisual management handbook: An in-depth look at the film, television and multimedia industry in Europe. Madrid: Media Business School. 
Pardo, A. (2014). Fundamentos de producción y gestión de proyectos audiovisuales. Pamplona: Eunsa.

Steemers, J. (2004). Selling television: British television in the global marketplace. Londres: BFI Publishing.

Szostak, S. (2013). Format adaptation and craftsmanship: Interview with Polish television writer Agnieszka Kruk. Critical Studies in Television, 8(2), 76-84.

Szostak, S. (2016). Fiction TV Formats in Poland - Why Bother to Adapt? En A. Esser, I. R. Smith y M. Á. Bernal-Merino (eds.), Media across borders: Localising TV, film and video games (pp. 167-182). Neueva York: Routledge.

The Wit (2014). The Wit Guide to Scripted Formats 2014. Recuperado de https://goo.gl/wU6ft8

Uribe-Jongbloed, E. y Espinosa-Medina, H. D. (2014). A clearer picture: Towards a new framework for the study of cultural transduction in audiovisual market trades. Observatorio, 8(1), 23-48.

Viljoen, D. (2002). Art of the deal: The essential guide to business affairs for television, film and new media producers. Londres: PACT.

Villagrasa, J. M. (1992). La producción de ficción narrativa en la televisión norteamericana (Tesis de doctorado, Universidad Autónoma de Barcelona, Barcelona, España).

\section{Entrevistas a profesionales}

Cooper, Duncan. Consultor (International Executive Producer), BBC Worldwide. Entrevista personal. Fecha: 14/05/2014.

García-Castrillón, María. Ejecutiva de Ventas de Boomerang TV International. Entrevista telefónica. Fecha: 08/02/2016. 
Madrona, Darío. Guionista, coordinador de guiones y productor ejecutivo (productora DobleFilo). Entrevista personal. Fecha: 28/11/2013.

Manubens, Ignacio. Subdirector de Ficción de Atresmedia Televisión. Entrevista telefónica. Fecha: 12 /02/2016.

Quintana, Gregorio. Antiguo Director General de Ficción de la productora Boomerang TV. Entrevista personal. Fecha: 16/12/2013. 